\title{
Observation with or without late radiotherapy is equivalent to early radiotherapy in high-risk prostate cancer after radical prostatectomy: A SEER- Medicare analysis on trends, survival outcomes and complications
}

\section{Young Suk Suk Kwon}

Rutgers Robert Wood Johnson Medical School

Wei Wang

Rutgers The State University of New Jersey

Arnav Srivastava

Rutgers Robert Wood Johnson Medical School

Thomas L Jang

Rutgers Robert Wood Johnson Medical School

\section{Singer A Eric}

Rutgers Robert Wood Johnson Medical School

Rahul R Parikh

Rutgers Robert Wood Johnson Medical School

Wun-Jae Kim

Chungbuk National University College of Medicine

Isaac Yi Kim ( $\nabla$ kimiy@cinj.rutgers.edu )

Rutgers Cancer Institute of New Jersey https://orcid.org/0000-0001-7167-8853

Research article

Keywords: prostate cancer, prostatectomy, radiotherapy, SEER-Medicare,

Posted Date: December 11th, 2019

DOl: https://doi.org/10.21203/rs.2.18541/v1

License: (c) (i) This work is licensed under a Creative Commons Attribution 4.0 International License.

Read Full License 
Version of Record: A version of this preprint was published at Prostate International on June 1st, 2021. See the published version at https://doi.org/10.1016/j.prnil.2020.10.002. 


\section{Abstract}

Introduction: While early radiotherapy (eRT) after radical prostatectomy (RP) has shown to improve oncologic outcomes in patients with high-risk prostate cancer $(\mathrm{PCa})$ in a recent clinical trial, controversy remains regarding its benefit. We aimed to illustrate national trends of post-RP radiotherapy and compare outcomes and toxicities in patients receiving eRT vs. observation with or without late radiotherapy (IRT).

Methods: Utilizing the Surveillance, Epidemiology and End Results (SEER)-Medicare data from 2001 to 2011, we identified 7557 patients with high-risk pathologic features after RP ( $\geq$ pT3N0 and/or positive surgical margins). Our study cohort was consisted of patients receiving RT within 6 months of surgery (eRT), those receiving RT after 6 months (IRT), and those never receiving RT (observation). Another subcohort, delayed RT (dRT), encompassed both IRT and observation. Trends of post-RP radiotherapy were compared using the Cochran-Armitage trend test. Cox regression models identified factors predictive of worse survival outcomes. Kaplan-Meier analyses compared the eRT and the dRT groups.

Results: Among those with pathologically confirmed high-risk PCa after RP, 12.7\% ( $n=959), 13.2 \%$ $(n=1710)$, and $74.1 \%(n=4888)$ underwent eRT, IRT, and observation without RT, respectively. Of these strategies, the proportion of men on observation without RT increased significantly over time $(p=0.004)$. Multivariable Cox regression model demonstrated similar outcomes between the eRT and the dRT groups. At a median follow up of 5.9 years, five-year overall and cancer-specific survival outcomes were more favorable in the dRT group, when compared to the eRT group. Radiation related toxicities, including urinary incontinence, erectile dysfunction, and urethral stricture, were higher in the eRT group when compared to the IRT group.

Conclusions: Our results suggest that a blanket adoption of the eRT in high-risk PCa based on clinical trials with limited follow up may result in overtreatment of a significant number of men and expose them to unnecessary radiation toxicity.

\section{Introduction}

Radical prostatectomy (RP) remains the gold standard surgical treatment for patients with clinically localized prostate cancer (PCa)[1]. For some patients, surgery alone may not provide long-term oncologic control, particularly in those with adverse pathologic features. These patients are at risk for biochemical recurrence (BCR) and eventual progression of disease after surgery. To reduce BCR rates, adjuvant radiotherapy has been recommended to treat post-RP patients with adverse pathologic characteristics such as extracapsular extension (ECE), seminal vesicle invasion (SVI), or positive surgical margin (PSM) [2-4]. Currently, American Urologic Association/American Society of Radiation Oncology (AUA/ASTRO) guidelines, backed by randomized clinical trial data, support offering adjuvant radiotherapy to high-risk patients[1, 4].

Despite the oncologic benefits of adjuvant radiotherapy, it may lead to potential overtreatment and unnecessarily expose patients radiation toxicities $[2,5,6]$. Salvage radiotherapy given to post-RP patients 
with a PSA relapse, represents an effort to reduce overtreatment while maintaining radiotherapy's oncologic benefits[7]. However, some critics argue that salvage radiotherapy compromises the efficacy of radiotherapy (RT), fearing that in waiting for PSA elevation, high-risk patients miss a narrow treatment window and that the disease becomes no longer 'salvageable.[8]'

Multiple retrospective and prospective studies have demonstrated that adjuvant radiotherapy may offer more favorable survival, when compared to salvage radiotherapy; however, patient selection in these prior studies may have driven these conclusions. Patients who were candidates for post-RP radiotherapy based on pathologic features and underwent observation without recurrence may not be captured in these prior studies as they received neither adjuvant nor salvage radiotherapy.

Therefore, comparing patients who received adjuvant radiotherapy versus the sum population of those undergoing observation with and without salvage radiation, may provide a more clinically relevant finding. In this study we aimed to examine the national trend of post-RP radiation utilization and to compare outcomes in those receiving early RT (eRT) (within 6 months of RP) versus those observation with or without late RT (dRT) (after 6 months following RP) groups. We examine their survival outcomes and complication rates using a large population-based database.

\section{Methods}

\section{Study Cohort}

Our study was approved by the institutional review board (IRB) at the Rutgers Cancer Institute of New Jersey. We used Surveillance, Epidemiology, and End Results (SEER)-Medicare database, which links patient demographic and tumor-specific data collected by SEER cancer registries to health care claims for Medicare enrollees. Our study cohort was defined to include patients with non-metastatic high-risk PCa characterized by pT3 and/or positive surgical margin (Fig. 1).

Information on the incidence of cancer was available from 16 SEER areas from January 1, 2001, through December 31,2011 , which covers $25 \%$ of the US population.[9] Staging of the cancer was performed according to the American Joint Committee on Cancer criteria.[10]

\section{Definitions of Variables}

The patient cohort was categorized into the following three treatment groups: The eRT group was defined as those who received RT within 6 months after RP. The IRT group was defined as those who received RT beyond 6 months after RP. The observation group was defined as post RP patients without RT. Lastly, the delayed radiotherapy (dRT) group was defined to include those who were observed as well as those who received RT after 6 months, representing the sum of the observation and IRT groups. Complications included adverse outcomes occurring within 12 months after RP when comparing the eRT and dRT 
groups. In contrast, when comparing the eRT and IRT groups, adverse outcomes were assessed within 12 months after RT.

Adjunctive androgen deprivation therapy (ADT) was defined as RT plus any ADT delivered 2 months before RT until any time 3 years after radiation. Salvage ADT was given 3 years after RT.[11] PSA data was not used in our analysis, nor in the definition of eRT, IRT, or dRT.[12] Complications associated with treatment were identified with ICD-9-CM and HCPCS codes from Medicare files (Supplementary Material 1).

\section{Statistical Analyses}

The Pearson's chi square test was used to compare sociodemographic and tumor characteristics when comparing the eRT and dRT groups. The Cochran-Armitage trend test examined the treatment patterns over years.

Cox proportional hazards regression models were employed to identify factors predictive of worse survival outcomes, including treatment strategies and other relevant variables. The Kaplan-Meier survival analyses were used to compare overall survival (OS) and cancer-specific survival (CCS) for the eRT and $\mathrm{dRT}$ groups, and to determine five-year overall and cancer-specific survival outcomes.

Statistical analyses were conducted using SAS software, version 9.4 (SAS Institute Inc., Cary, NC, USA) and R statistical package, version 3.5.1 (https://www.r-project.org/). A two-sided p value $<0.05$ was considered statistically significant.

\section{Results}

\section{Cohort Characteristics and National Trends}

Among 7557 post-RP patients who met inclusion criteria, 12.7\% $(n=959)$ received eRT within 6 months following RP. Those who were observed and received RT after 6 months as needed basis accounted for $87.3 \%(n=6598)$, representing the dRT group. In this latter group, $4888(74.1 \%)$ patients never underwent radiation treatment (Fig. 1).

Comparing the eRT and dRT groups in terms of pathologic characteristics, there were significant differences in tumor stage and Gleason score patterns $(P<0.0001)$ (Table 1). The eRT group contained a lower proportion of organ-confined disease (14.50\% vs. $32.59 \%)$ and greater proportion of extra-capsular extension (24.92\% vs. $14.19 \%)$ compared to the dRT group. While adjunctive ADT was more commonly used in the eRT group when compared to the dRT group (52.55 vs. 16.96; $P<0.0001$ ), salvage ADT was exclusively used in the dRT setting ( 0.15 vs. $0 ; P=0.63)$ (Table 1$)$. A steady increase in men who were managed with observation was noted ( $p$ trend $=0.004)($ Fig. 2). 


\section{Survival Analyses}

At a median follow-up of 5.9 years (95\% Confidence Interval (CI): 5.8, 6.0), there were 837 deaths in the cohort of 7557 men, of which 199 were attributed to prostate cancer. Extra-capsular disease with pathologic staging ${ }^{3}$ pT3 confers worse OS and CSS when compared to those with organ-confined disease (pT3-NXM0 vs. pT2+NOM0: Hazard Ratio (HR) 1.58 (95\% Cl:1.04, 2.40) for OS and HR 2.46 (95\% Cl: $1.04,5.84)$ for CSS).

A similar trend, with a higher HR, was observed in patients with $\mathrm{pT} 4$ staging when compared to men with organ-confined disease (OS - PT4NOMO vs. PT2+NOMO: HR = 3.05 (95\% Cl: 1.81, 5.15); CSS - HR = 3.60 $(95 \% \mathrm{Cl}: 1.33,9.74))$. Gleason score 8-10 also predicted cancer-specific mortality when compared to those with Gleason 6 disease (CSS - HR $=8.51$ (95\% Cl: 2.99, 24.27)). Types of radiation therapy, eRT vs. dRT, had similar effects on both OS and CSS when adjusted for pathologic staging and Gleason grades (eRT vs. $\mathrm{dRT}$ : OS - HR = 1.06 (95\% Cl: 0.78, 1.43);CSS - HR = 0.69 (95\% Cl: 0.42, 1.11)) (Table 2).

Five-year OS probabilities of the eRT group and that of dRT group were not statistically significantly different (0.92 vs. $0.94 ; P=0.95)$. Similarly, five-year CSS probabilities of both groups were similar as well (0.96 vs. $0.99 ; P=0.93$ ). Kaplan-Meier survival curves demonstrate that the $d R T$ group had superior OS and CSS when compared to the eRT group (log rank $\mathrm{P}<0.001$ for both) (Figure 3 ). When comparing individuals with RT at different time intervals, eRT vs. IRT, both groups had similar OS and CSS (log rank $\mathrm{P}=0.78$ and 0.85 for OS and CSS, respectively) (Figure not shown).

\section{Adverse Outcomes}

Patients who had eRT experienced more complications than those who had dRT in terms of radiation cystitis $(0.94 \%$ vs. $0.06 \% ; \mathrm{P}<0.001)$ and radiation proctitis $(1.04 \%$ vs. $0.09 \% ; \mathrm{P}<0.001)$. However, a greater proportion of men who had dRT had erectile dysfunction $(42.30 \%$ vs $33.68 \% ; P<0.0001)$ and subsequent procedures to address erectile dysfunction (6.49\% vs $3.96 \% ; P=0.0023)$ (Supplementary Table 1).

When comparing two RT groups without those individuals who were observed, namely the eRT vs. IRT groups, more complications were seen in the eRT group in terms of urinary incontinence $(27.84 \% \mathrm{vs}$. $17.84 \% ; P<0.0001)$, erectile dysfunction (30.76\% vs. $21.70 \% ; P<0.0001)$, and bladder neck contracture (14.60\% vs. $9.36 \% ; P<0.0001)$ (not shown).

\section{Discussion}

Despite the AUA/ASTRO guideline for adjuvant radiotherapy for post RP patients with adverse pathologic features, our study found that 12.6\% (959/7557) of eligible patients received radiotherapy within 6 months of RP (eRT). Furthermore, we observed an increasing utilization of the observation strategy $(\mathrm{p}$ trend $=0.004$ ). Additionally, we observed similar OS and CSS between the eRT and dRT groups. Radiation 
toxicity impacted the eRT group more than the dRT group, and this finding persisted even when the observation-only patients was removed in the dRT group.

With comparable survival outcomes and significantly less treatment-related toxicities seen in the dRT group, our findings suggest that an increasing proportion of patients might safely adopt the strategy of initial observation followed by radiation as needed. This may preserve oncologic benefits of radiotherapy and spare many patient radiation toxicities.

The magnitude of oncologic benefit from adjuvant radiation demonstrated in prior studies, may be overstated by study population selection[2]. Adjuvant radiation has been incorporated into the NCCN guidelines based on two randomized prospective studies (EORTC and SWOG) [4, 13-15]. Although these studies demonstrated benefit from adjuvant radiotherapy when compared to the control group, these comparisons might have been biased because no uniform treatments were rendered to patients on recurrence in the observation cohort. Without prompt interventions, these affected individuals are bound to experience poor survival outcomes, which led to controversial recommendation.

In this regard, our study demonstrates that $74 \%$ of men who are eligible for eRT do not recur with observation- based on the fact that they did not require IRT. Simultaneously, we found similar survival outcomes in the dRT group when compared to the eRT group in terms of both OS and CSS. Furthermore, Kaplan-Meier survival analyses comparing the eRT and the dRT group uniformly show survival advantage of the dRT group (Fig. 3).

When adjusting for patient and neoplasm features that may portend poorer outcomes, multivariable Cox regression demonstrated only Gleason 8-10 (OS - HR $=1.56$ (95\% Cl: 1.09, 2.23; CSS - HR $=8.51(95 \%$ Cl: $2.99,24.27)$ ) and pT4NOMO (OS - HR = 3.05(95\% Cl: 1.81, 5.15);CSS - HR = 3.60(95\% Cl: 1.33, 9.74)) as predictors of worse survival outcomes. Timing of radiation (eRT vs. dRT) did not independently predict worse survival outcomes.

Our analysis is consistent with Fossati et al. who showed no long-term differences in terms of distant metastasis and mortality when comparing adjuvant radiotherapy against initial observation followed by early salvage radiotherapy[16]. On the other hand, a recent randomized control trial from the FinnProstate Group with 250 enrolled patients showed the opposite: The lower biochemical recurrence was seen in the adjuvant radiotherapy group when compared to those who were observed. However, it is critical to note that lower biochemical recurrence did not translate into superior OS or CSS. Moreover, it should also be emphasized that $57.3 \%(70 / 122)$ in the observation group remained progression free[17]. Therefore, both our study and this recent trial support that observation followed by future radiation upon recurrence may provide an acceptable alternative to automatic early intervention with RT. Moreover, many studies that report superior oncologic outcomes of adjuvant radiotherapy in comparison to salvage radiotherapy often utilize heterogeneous and highly elevated PSA levels at which salvage radiotherapy was initiated. [18] 
In addition to survival outcomes a discussion of treatment-related toxicities is a critical outcome for post RP patients facing choices between eRT and dRT. It is previously reported that urinary symptoms are typically well tolerated and the majority of patients achieved the baseline symptoms after both eRT and dRT.[5] Similarly, Shumway et al. demonstrates that post-RP patients generally tolerate RT both adjuvant and salvage settings in the retrospective review of 85 patients.[19] However, our study clearly demonstrated an increased risk of radiation cystitis $(P<0.001)$ and requiring procedures for bladder neck contracture following eRT $(P=0.013)$ when compared to the $d R T$ setting (Supplementary table 1$)$.

Worse complications seen in patients with the eRT group, when compared to IRT, may indicate that RT in the immediate postoperative setting may interfere with tissue healing and compromise the recovery of urinary function (urinary incontinence: $27.8 \%$ vs. $17.8 \%, \mathrm{P}<0.001$ ) (Supplementary table 2). Those who underwent $\mathrm{eRT}$ also had more bladder neck contracture and thus required more operative procedures, when compared to those who underwent IRT (procedures: $7.72 \%$ vs. $2.92 \% ; \mathrm{P}<0.001$ ). Lastly, secondary cancer risks after RT is beyond the scope of this study but may represent important treatment-related side effects[20].

Despite high-level published data supporting the use of adjuvant radiotherapy, only $12.6 \%$ of patients received eRT. Interestingly, the increase of observation strategy seen in the period of 2001 and 2011 may coincide with the previous finding $(P$ trend $<0.0041)$. For example, Sineshaw et al. reported a steady decrease in postoperative RT within 6 months of RP from 9.1-7.3\% ( $P$ trend $<0.001)[21]$. A trend favoring observation may reflect an improvement in risk-stratification for better selection of higher risk patients for upfront radiation to leave the rest for close surveillance.

Our study has several important limitations. First, inherent to our SEER-Medicare database, our study is a retrospective cohort study which contains significant confounders- some controllable but others not. Second, the lack of PSA levels in the data set precludes precise assignment of eRT, as opposed to dRT. Third, limited information on types and doses of radiation is available. It is likely that a substantial heterogeneity exists in this cohort in terms of types of RT and doses. Fourth, complications are not graded based on severity, and hence, may not provide a comprehensive clinical picture.

Ultimately, the decision between eRT and dRT will be answered by the multiple prospective randomized trials. Specifically, both RADICALS RT and RAVES trials compare adjuvant radiotherapy and salvage radiotherapy with primary endpoints of disease-specific survival and biochemical failure, respectively. Other trials including RADICALS HD, GETUG-17, and EORTC 22043-30041 implemented androgen deprivation therapy in the both comparison arms based on recent evidence of ADT use in improved survival.[22] In the meantime, we recommend that $\mathrm{dRT}$ may be the preferred approach over adjuvant radiotherapy based on equivalent oncologic outcome and superior quality of life.

\section{Conclusions}

Our results demonstrated a relatively low utilization of adjuvant radiotherapy given within 6 months after RP. In terms of oncologic control, patients who were either observed or had a delayed radiotherapy after 6 
months had similar survival rates as those who were given adjuvant radiotherapy. Given the similar survival outcomes associated with observation with salvage radiation and better safety profiles with significantly less toxicities, a greater proportion of patients may in fact benefit from an observation with radiotherapy as needed as opposed to adjuvant therapy.

\section{Abbreviations}

ADT:Androgen deprivation therapy; CSS:Cancer-specific survival; dRT:Delayed radiotherapy; eRT:Early radiotherapy; HR:Hazard ratio; INF:Infinity; OS:Overall survival; PCa:Prostate cancer; PSA:Prostate-specific antigen; RP:Radical prostatectomy; RT:Radiotherapy; SEER:Surveillance, Epidemiology, and End Results

\section{Declarations}

\section{Ethics approval and consent to participate}

This study was approved by the Rutgers Biomedical and Health Sciences Institutional Review Board (Reference: Pro20150002331). Furthermore, the principles of the Helsinki Declaration were followed. Our board exempted informed consent because this was a retrospective study using the SEER-Medicare database

\section{Consent for publication}

Not applicable; this manuscript does not present data relating to any individual persons.

\section{Availability of data and materials}

The datasets used and/or analyzed during the current study are available from the corresponding author on reasonable request.

\section{Competing interests}

None of the contributing authors have any conflicts of interest, including specific financial interests and relationships and affiliation relevant to the subject matter or materials discussed in the manuscript.

\section{Funding}

This work was supported by the cancer center grant from the National Cancer Institute (Grant P30CA072720) and generous support from the Marion and Norman Tanzman Charitable Foundation and Mr. Malcolm Wernik.

\section{Authors' contributions}

YSK, WW, and AS reviewed the pertinent literature, analyzed the results, and drafted and edited the manuscript. IYK was responsible for the entire project. He designed the study concept, guided the study 
design, conducted data acquisition, and revised the manuscript critically for important intellectual content. TLJ, EAS, RRP, and WJK analyzed data, and revised the manuscript. All authors read and approved the final manuscript.

\section{Acknowledgements}

None.

\section{References}

1. Sanda MG, Cadeddu JA, Kirkby E, Chen RC, Crispino T, Fontanarosa J, Freedland SJ, Greene K, Klotz LH, Makarov DV et al: Clinically Localized Prostate Cancer: AUAVASTRO/SUO Guideline. Part II: Recommended Approaches and Details of Specific Care Options. The Journal of Urology 2018, 199(4):990-997.

2. Gandaglia G, Briganti A, Clarke N, Karnes RJ, Graefen M, Ost P, Zietman AL, Roach M, 3rd: Adjuvant and Salvage Radiotherapy after Radical Prostatectomy in Prostate Cancer Patients. Eur Uro/ 2017, 72(5):689-709.

3. Leyh-Bannurah S-R, Gazdovich S, Budäus L, Zaffuto E, Dell'Oglio P, Briganti A, Abdollah F, Montorsi F, Schiffmann J, Menon M et al: Population-Based External Validation of the Updated 2012 Partin Tables in Contemporary North American Prostate Cancer Patients. The Prostate 2017, 77(1):105-113.

4. Bolla M, van Poppel H, Collette L, van Cangh P, Vekemans K, Da Pozzo L, de Reijke TM, Verbaeys A, Bosset J-F, van Velthoven $\mathrm{R}$ et al: Postoperative radiotherapy after radical prostatectomy: a randomised controlled trial (EORTC trial 22911). The Lancet 2005, 366(9485):572-578.

5. Pinkawa M, Fischedick K, Asadpour B, Gagel B, Piroth MD, Holy R, Krenkel B, Eble MJ: Health-related quality of life after adjuvant and salvage postoperative radiotherapy for prostate cancer - a prospective analysis. Radiother Oncol 2008, 88(1):135-139.

6. Kowalczyk KJ, Gu X, Nguyen PL, Lipsitz SR, Trinh QD, Lynch JH, Collins SP, Hu JC: Optimal timing of early versus delayed adjuvant radiotherapy following radical prostatectomy for locally advanced prostate cancer. Urol Oncol 2014, 32(3):303-308.

7. Stephenson AJ, Bolla M, Briganti A, Cozzarini C, Moul JW, Roach lii M, van Poppel H, Zietman A: Postoperative Radiation Therapy for Pathologically Advanced Prostate Cancer After Radical Prostatectomy. European Urology 2012, 61(3):443-451.

8. Slawin KM: Radiation therapy after radical prostatectomy: why patience is a virtue! The case for salvage radiation therapy. Reviews in urology 2002, 4(2):90-94.

9. Warren JL, Klabunde CN, Schrag D, Bach PB, Riley GF: Overview of the SEER-Medicare data: content, research applications, and generalizability to the United States elderly population. Med Care 2002, 40(8 Suppl):Iv-3-18.

10. Amin MB, Greene FL, Edge SB, Compton CC, Gershenwald JE, Brookland RK, Meyer L, Gress DM, Byrd DR, Winchester DP: The Eighth Edition AJCC Cancer Staging Manual: Continuing to build a bridge 
from a population-based to a more "personalized" approach to cancer staging. CA Cancer J Clin 2017, 67(2):93-99.

11. Jang TL, Han M, Roehl KA, Hawkins SA, Catalona WJ: More favorable tumor features and progression-free survival rates in a longitudinal prostate cancer screening study: PSA era and threshold-specific effects. Urology 2006, 67(2):343-348.

12. Adamo M, Boten JA, Coyle LM, Cronin KA, Lam CJK, Negoita S, Penberthy L, Stevens JL, Ward KC: Validation of prostate-specific antigen laboratory values recorded in Surveillance, Epidemiology, and End Results registries. Cancer 2017, 123(4):697-703.

13. Thompson IM, Jr., Tangen CM, Paradelo J, Lucia MS, Miller G, Troyer D, Messing E, Forman J, Chin J, Swanson $\mathrm{G}$ et al: Adjuvant radiotherapy for pathologically advanced prostate cancer: a randomized clinical trial. Jama 2006, 296(19):2329-2335.

14. Wiegel T, Bottke D, Steiner U, Siegmann A, Golz R, Storkel S, Willich N, Semjonow A, Souchon R, Stockle $\mathrm{M}$ et al: Phase III postoperative adjuvant radiotherapy after radical prostatectomy compared with radical prostatectomy alone in pT3 prostate cancer with postoperative undetectable prostatespecific antigen: ARO 96-02/AUO AP 09/95. J Clin Onco/ 2009, 27(18):2924-2930.

15. Wiegel T, Bartkowiak D, Bottke D, Bronner C, Steiner U, Siegmann A, Golz R, Storkel S, Willich N, Semjonow A et al: Adjuvant radiotherapy versus wait-and-see after radical prostatectomy: 10-year follow-up of the ARO 96-02/AUO AP 09/95 trial. Eur Urol 2014, 66(2):243-250.

16. Fossati N, Karnes RJ, Colicchia M, Boorjian SA, Bossi A, Seisen T, Di Muzio N, Cozzarini C, Noris Chiorda B, Fiorino C et al: Impact of Early Salvage Radiation Therapy in Patients with Persistently Elevated or Rising Prostate-specific Antigen After Radical Prostatectomy. European Urology 2018, 73(3):436-444.

17. Hackman G, Taari K, Tammela TL, Matikainen M, Kouri M, Joensuu T, Luukkaala T, Salonen A, Isotalo T, Petas A et al: Randomised Trial of Adjuvant Radiotherapy Following Radical Prostatectomy Versus Radical Prostatectomy Alone in Prostate Cancer Patients with Positive Margins or Extracapsular Extension. Eur Urol 2019.

18. Hwang WL, Tendulkar RD, Niemierko A, Agrawal S, Stephans KL, Spratt DE, Hearn JW, Koontz BF, Lee WR, Michalski JM et al: Comparison Between Adjuvant and Early-Salvage Postprostatectomy Radiotherapy for Prostate Cancer With Adverse Pathological FeaturesComparison Between Adjuvant and Early-Salvage Postprostatectomy Radiotherapy for Prostate CancerComparison Between Adjuvant and Early-Salvage Postprostatectomy Radiotherapy for Prostate Cancer. JAMA Oncology 2018, 4(5):e175230-e175230.

19. Shumway D, Daignault S, Feng F, Jackson W, Johnson S, Miller D, Wei J, Hamstra D: Is the Fear of Postprostatectomy Radiation Therapy Justified?: An Analysis of Patient-Reported Quality of Life Following Adjuvant or Salvage Radiation. International Journal of Radiation Oncology • Biology • Physics 2014, 90(1):S460-S461.

20. Bostrom PJ, Soloway MS: Secondary cancer after radiotherapy for prostate cancer: should we be more aware of the risk? Eur Urol 2007, 52(4):973-982. 
21. Sineshaw HM, Gray PJ, Efstathiou JA, Jemal A: Declining Use of Radiotherapy for Adverse Features After Radical Prostatectomy: Results From the National Cancer Data Base. Eur Urol 2015.

22. Jackson WC, Schipper MJ, Johnson SB, Foster C, Li D, Sandler HM, Palapattu GS, Hamstra DA, Feng FY: Duration of Androgen Deprivation Therapy Influences Outcomes for Patients Receiving Radiation Therapy Following Radical Prostatectomy. Eur Urol 2016, 69(1):50-57.

\section{Tables}

Table 1: Demographic and Clinicopathologic Characteristics 


\begin{tabular}{|c|c|c|c|}
\hline Characteristics & $\begin{array}{l}\mathrm{RP}+ \\
\mathrm{eRT} \\
(\mathrm{N}= \\
959)\end{array}$ & $\begin{array}{l}\mathrm{RP}+ \\
\mathrm{dRT} \\
(\mathrm{N}=6 \\
598)\end{array}$ & $\begin{array}{l}\mathrm{P} \\
\text { Value }\end{array}$ \\
\hline Age at diagnosis, y (\%) & & & 0.3227 \\
\hline $65-69$ & 62.98 & 60.84 & \\
\hline $70-74$ & 30.66 & 31.54 & \\
\hline $75-79$ & 6.15 & 6.94 & \\
\hline $80-84$ & 0.21 & 0.64 & \\
\hline $85+$ & 0.00 & 0.04 & \\
\hline Race (\%) & & & 0.0981 \\
\hline White & 82.59 & 83.84 & \\
\hline Black & 7.92 & 8.52 & \\
\hline Other & 9.49 & 7.49 & \\
\hline Unknown & 0.00 & 0.15 & \\
\hline Hispanic ethnicity (\%) & & & 0.2276 \\
\hline Not Hispanic & 97.71 & 98.12 & \\
\hline Hispanic & 2.29 & 1.73 & \\
\hline Unknown & 0.00 & 0.15 & \\
\hline Marital status (\%) & & & 0.5564 \\
\hline Married & 82.06 & 80.65 & \\
\hline Unmarried & 14.39 & 15.34 & \\
\hline Unknown & 3.55 & 4.01 & \\
\hline Tumor stage ${ }^{a}(\%)$ & & & $<.0001$ \\
\hline pT2+NOMO & 10.64 & 21.19 & \\
\hline pT2+NXMO & 3.86 & 11.40 & \\
\hline pT3+NOMO & 20.54 & 10.28 & \\
\hline pT3+NXMO & 4.38 & 3.91 & \\
\hline pT3-NOMO & 43.17 & 38.33 & \\
\hline pT3-NXMO & 12.20 & 12.29 & \\
\hline
\end{tabular}




\begin{tabular}{|c|c|c|c|}
\hline pT4NOMO & 3.96 & 1.99 & \\
\hline pT4NXMO & 1.25 & 0.61 & \\
\hline Gleason pattern ${ }^{\mathrm{b}}(\%)$ & & & $<.0001$ \\
\hline $3+3$ & 6.66 & 16.76 & \\
\hline $3+4$ & 25.52 & 39.13 & \\
\hline $4+3$ & 16.64 & 19.43 & \\
\hline $8-10$ & 45.35 & 19.12 & \\
\hline Unknown & 5.83 & 5.55 & \\
\hline Diagnosis year (\%) & & & 0.0524 \\
\hline $2001-2003$ & 24.82 & 26.30 & \\
\hline $2004-2006$ & 24.09 & 23.02 & \\
\hline $2007-2009$ & 28.68 & 31.49 & \\
\hline $2010-2011$ & 22.41 & 19.19 & \\
\hline SEER registry (\%) & & & $<.0001$ \\
\hline Atlanta & 1.46 & 1.82 & \\
\hline Connecticut & 4.48 & 5.50 & \\
\hline Detroit & 5.84 & 7.05 & \\
\hline Greater California & 23.36 & 24.60 & \\
\hline Greater Georgia & 7.82 & 6.26 & \\
\hline Hawaii & 3.23 & 1.56 & \\
\hline lowa & 2.82 & 5.11 & \\
\hline Kentucky & 6.99 & 6.46 & \\
\hline Los Angeles & 13.45 & 11.35 & \\
\hline Louisiana & 7.72 & 7.70 & \\
\hline New Jersey & 10.74 & 7.96 & \\
\hline New Mexico & 2.19 & 2.73 & \\
\hline Rural Georgia & 0.00 & 0.06 & \\
\hline San Francisco & 3.13 & 2.88 & \\
\hline San Jose & 2.40 & 2.39 & \\
\hline
\end{tabular}


Utah

$4.37 \quad 6.57$

Population of county of residence (\%)

$>=1000000$

$52.35 \quad 50.91$

$250000-999999$

$24.92 \quad 24.95$

$0-249999$

$22.73 \quad 24.14$

Percentage with less than a high school education in census tract of residence, $\%{ }^{\mathrm{c}}(\%)$

Bottom quartile (24-100)

$26.17 \quad 24.11$

Second quartile (13-24)

$26.80 \quad 26.30$

Third quartile (7-13)

$23.57 \quad 24.08$

Top quartile (0-7)

$23.25 \quad 25.01$

Unknown

$0.21 \quad 0.50$

Median household income in census tract of residence, US\$c (\%)

Bottom quartile (0-36 916)

Second quartile (36 916-50 213)

Third quartile (50 213-69 539)

Top quartile (69 539-200 014)

Unknown

Adjunctive ADT Use after RP (\%)

Yes

No

Salvage ADT Use after RP (\%)

Yes

No
$24.61 \quad 24.95$

$25.03 \quad 24.86$

$26.49 \quad 24.64$

$23.67 \quad 25.05$

$0.20 \quad 0.50$
$52.55 \quad 16.96$

$47.45 \quad 83.04$

Abbreviations: eRT: early radiotherapy; dRT: delayed radiotherapy; RP, radical prostatectomy; ADT, androgen deprivation therapy; SEER, Surveillance, Epidemiology, and End Results.

a"+" and "-" in tumor stage represent positive and negative surgical margins. 
${ }^{b}$ Data collection for Gleason pattern in SEER began in 2004, and number of patients involved in Gleason pattern distribution in RP + dRT group and RP + eRT group were 4863 and 721, respectively.

${ }^{C}$ Educational level and median household income were based on census tract data (year 2000). The top educational quartile represents the highest educated group.

Table 2: Multivariable Cox Proportional Hazards Regression Analyses for Overall and Prostate CancerSpecific Survivals

\begin{tabular}{|c|c|c|}
\hline Characteristics & $\begin{array}{l}\text { Overall Survival } \\
\text { HR }(95 \% \mathrm{Cl})\end{array}$ & $\begin{array}{l}\text { PCa Specific Survival } \\
\text { HR }(95 \% \mathrm{Cl})\end{array}$ \\
\hline \multicolumn{3}{|l|}{ Treatment } \\
\hline eRT & 1.00 (reference) & 1.00 (reference) \\
\hline $\mathrm{dRT}$ & $0.94(0.70,1.28)$ & $0.69(0.42,1.11)$ \\
\hline \multicolumn{3}{|l|}{ Tumor stage ${ }^{a}$} \\
\hline pT2+NOMO & 1.00 (reference) & 1.00 (reference) \\
\hline pT2+NXM0 & $1.18(0.75,1.87)$ & $0.80(0.21,3.04)$ \\
\hline pT3+NOMO & $1.22(0.78,1.90)$ & $0.90(0.33,2.44)$ \\
\hline pT3+NXMO & $1.17(0.62,2.22)$ & $1.26(0.33,4.78)$ \\
\hline pT3-NOMO & $1.72(1.23,2.42)$ & $1.61(0.74,3.49)$ \\
\hline pT3-NXMO & $1.58(1.04,2.40)$ & $2.46(1.04,5.84)$ \\
\hline pT4NOMO & $3.05(1.81,5.15)$ & $3.60(1.33,9.74)$ \\
\hline pT4NXM0 & $1.06(0.26,4.39)$ & $N A^{b}$ \\
\hline \multicolumn{3}{|l|}{ Gleason pattern } \\
\hline $3+3$ & 1.00 (reference) & 1.00 (reference) \\
\hline $3+4$ & $0.94(0.67,1.32)$ & $1.08(0.34,3.36)$ \\
\hline $4+3$ & $0.85(0.57,1.27)$ & $1.77(0.55,5.75)$ \\
\hline $8-10$ & $1.56(1.09,2.23)$ & $8.51(2.99,24.27)$ \\
\hline
\end{tabular}

Abbreviations: eRT: early radiotherapy; dRT: delayed radiotherapy; PCa: prostate cancer; HR, hazard ratio; $\mathrm{Cl}$, confidence interval; INF, infinity; SEER, Surveillance, Epidemiology, and End Results.

a"+" and "-" in tumor stage represent positive and negative surgical margins. 
${ }^{b}$ No death event was found for men in either treatment regimen ( $R P+d R T$ or $\left.R P+e R T\right)$.

\section{Note On Supplementary Tables}

Supplementary Table 3 was not included in this manuscript version.

\section{Figures}

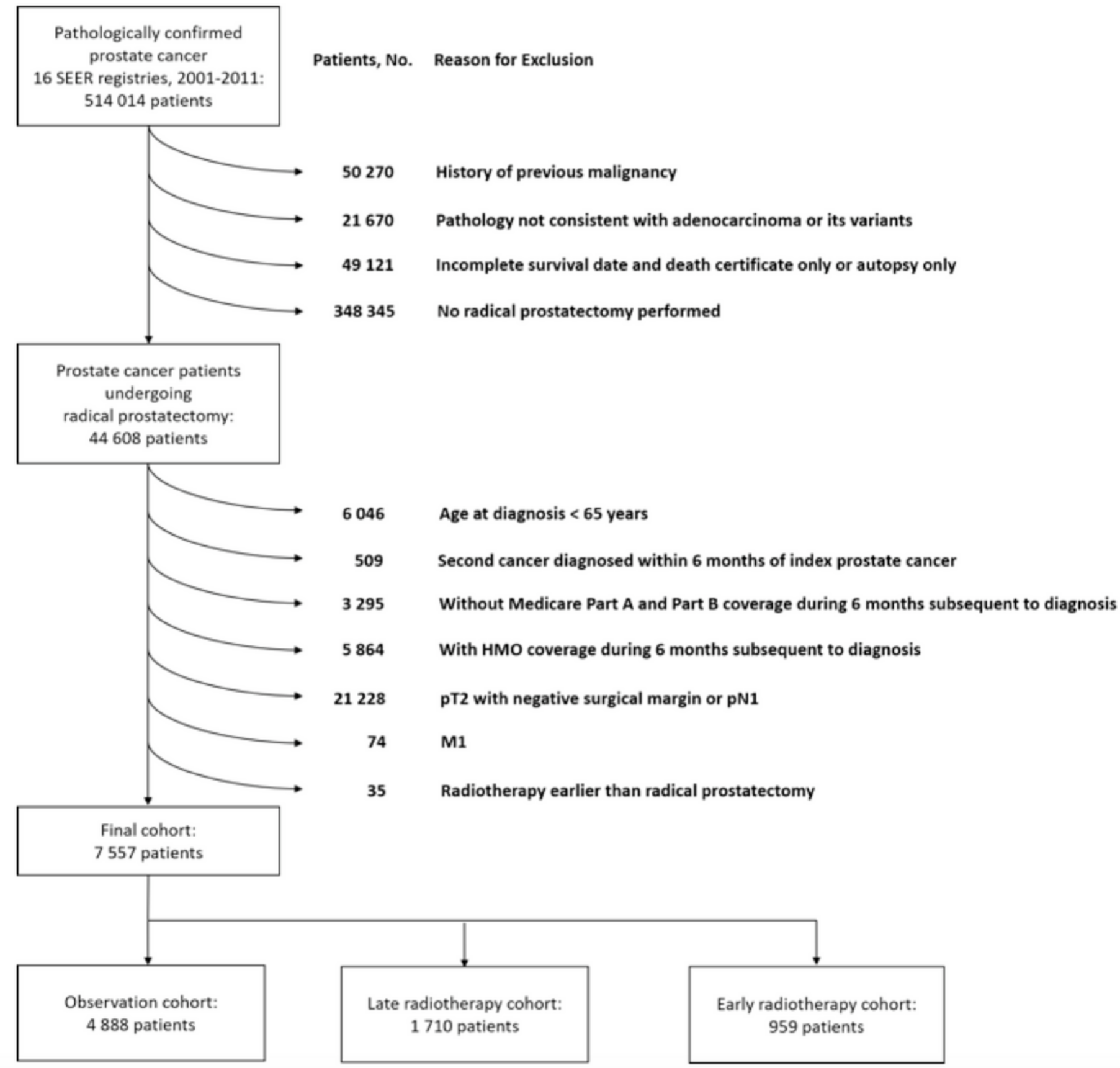

Figure 1 
Flow Chart for Inclusion and Exclusion of Study Population

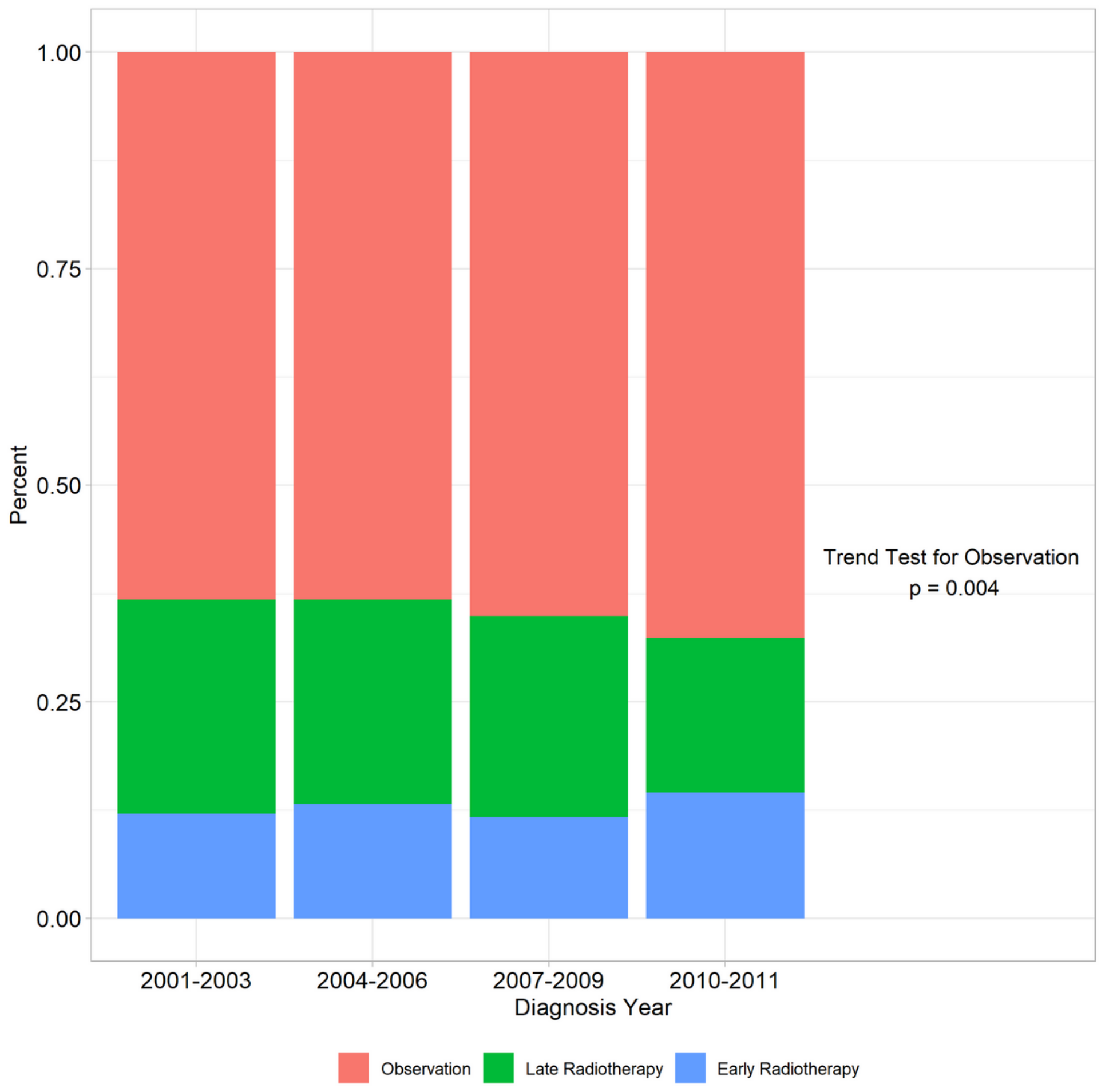

Figure 2

Trends of Radiotherapy Post-Prostatectomy 
Overall Survival: early RT < 6 months < delayed RT

group $\mp$ eRT $+\mathrm{dRT}$

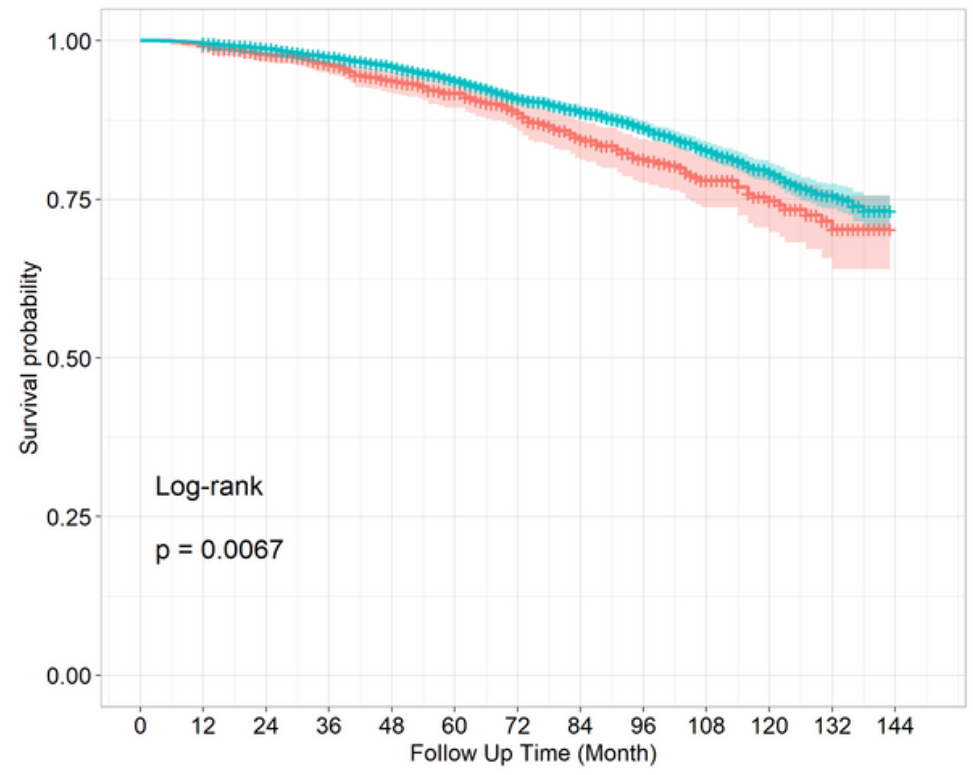

Number at risk

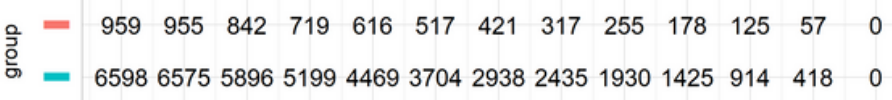

PCa Specific Survival: early RT < 6 months < delayed RT

group + eRT $+\mathrm{dRT}$

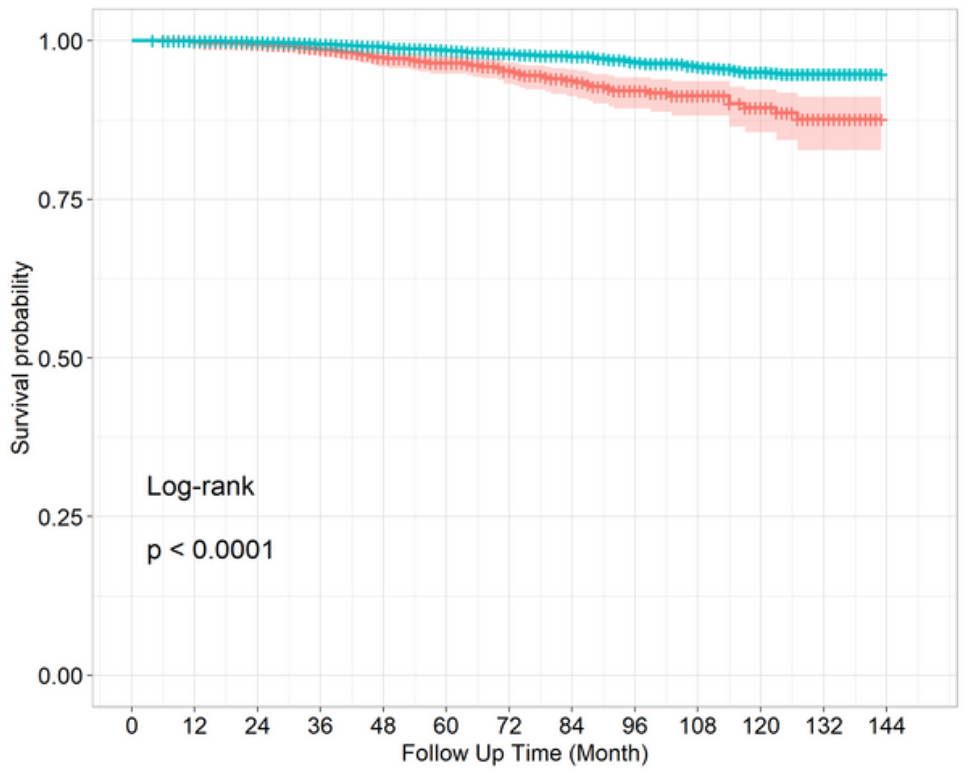

Number at risk

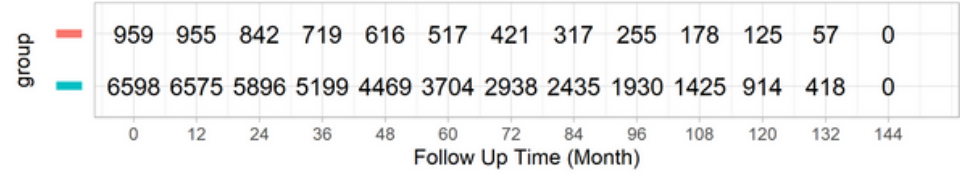

\section{Figure 3}

Overall and Prostate Cancer Specific Survival: Early vs. Delayed Radiotherapy 